\title{
Technologia wykonania konstrukcji osłony odzawałowej obudowy kopalnianej - montaż i spawanie elementów oraz kontrola osłony odzawałowej
}

\section{The technology of making a construction of an anti-breaking down mining support - welding and assembling elements and controlling anti-breaking down support}

\section{Streszczenie}

Omówiono wymagania stawiane osłonom odzawałowym obudów kopalnianych. Przedstawiono etapy montażu elementów obudowy oraz Karty Technologiczne Montażu zgodnie z którymi montaż jest realizowany. Omówiono spawanie elementów. Zaprezentowano kontrolę wymiarową oraz kontrolę złączy spawanych. Przedstawiono zagadnienia obróbki wiórowej niezbędnej w procesie technologicznym wytwarzania obudowy.

Słowa kluczowe: technologia spawania; projektowanie technologii; konstrukcja spawana

\section{Abstract}

In the following paper specifications relating to anti-breaking mining supports were provided. Successive stages of assembling the elements of support and Assembly Operation Sheets were presented. Welding of elements was described. Dimensional control and welded joints control were discussed. The issues referring to machining essential in the technological process of manufacturing the support were given.

Keywords: welding procedure specification; design of weIding procedure; welding structure

\section{Wstęp}

Publikacja stanowi trzecią część cyklu prezentującego proces wytwarzania konstrukcji spawanej obudowy górniczej. W poprzedniej części przedstawiono zagadnienia dotyczące podgrzewania wstępnego i temperatury warstw pośrednich, uprawnień spawaczy oraz realizacji procesu spawania. Omówiono proces młotkowania i wymagania dla powierzchni lica spoiny. Podano wymagania dotyczące spawania, w tym przeciwdziałania występowania pęcherzy, spawania w narożach, wykonywania spoin wielowarstwowych, zakończenia ściegów. Przedstawiono sposoby odprężania konstrukcji oraz warunki prowadzenia napraw wadliwych odcinków spoin.

W bieżącej publikacji omówiono zagadnienia dotyczące wymagań konstrukcyjnych stawianych osłonie odzawałowej, przedstawiono montaż i spawanie elementów osłony oraz kontrolę złączy spawanych $[1 \div 19]$.

\section{Osłona zmechanizowana - informacje ogólne}

Obudowy zmechanizowane (rys. 1) przeznaczone są do podtrzymywania i kierowania stropem w kopalniach wę- gla kamiennego w poziomych i nachylonych wyrobiskach ścianowych, w systemie ścianowym podłużnym na pełny zawał. W kompleksach ścianowych obudowy współpracują z kombajnem ścianowym oraz przenośnikiem ścianowym zgrzebłowym. W pokładach o nachyleniu podłużnym powyżej $10^{\circ}$ kompleks ścianowy wyposażony jest w urządzenia do stabilizacji dolnych sekcji przenośnika, korygowania

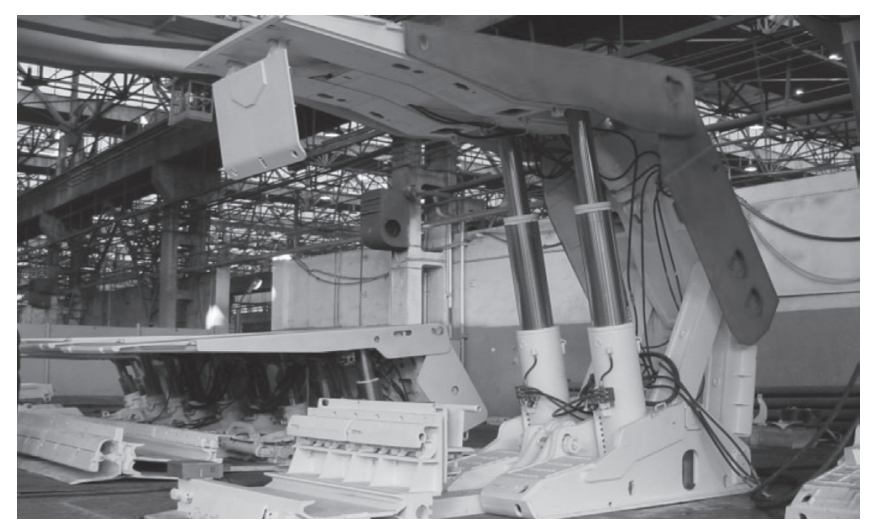

Rys. 1. Widok kasztu obudowy zmechanizowanej Fig. 1. A view of a crib of a mechanized support

Dr hab. inż. Jacek Słania, prof. P.Cz - Politechnika Częstochowska; mgr inż. Henryk Marcinkiewicz - FMG PIOMA SA GRUPA FAMUR; mgr inż. Mariusz Kiełbik - FMG PIOMA SA GRUPA FAMUR.

Autor korespondencyjny/Corresponding author. jacek_slania@poczta.onet.pl 
stropnic i zabezpieczenia dolnej sekcji na upadach. Korygowanie położenia obudowy, zwłaszcza w ścianach nachylonych, zapewniają układy korekcji sekcji.

Konstrukcja obudowy zapewnia mechanizację następujących prac:

- rozparcie zestawu automatycznie określoną odpornością wstępną

- podtrzymanie stropu ze stałą odpornością roboczą

- rabowanie zestawu obudowy,

- przesuwanie sekcji za postępującym czołem ściany,

- korygowanie położenia sekcji, przesuwanie przenośnika ścianowego,

- podparcie stropu w części przyczołowej ściany za pomocą wysięgnika przegubowo - wysuwnego,

- osłonięcie czoła ściany w celu zapewnienia bezpiecznych warunków pracy dla obsługi [20]

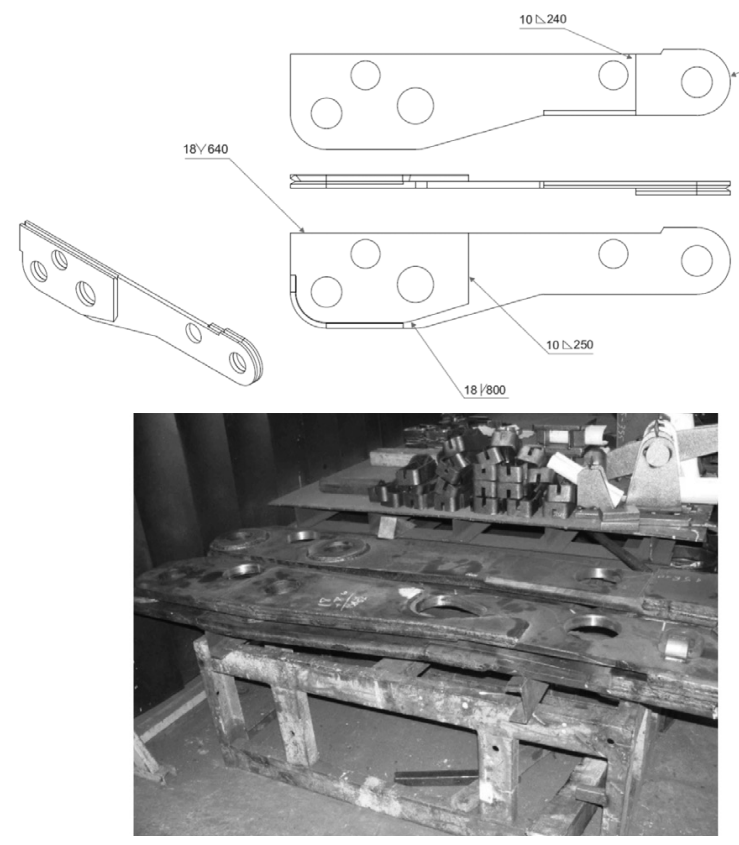

Rys. 2. Pospawany tężnik z nakładkami

Fig. 2. Welded brace with butt straps
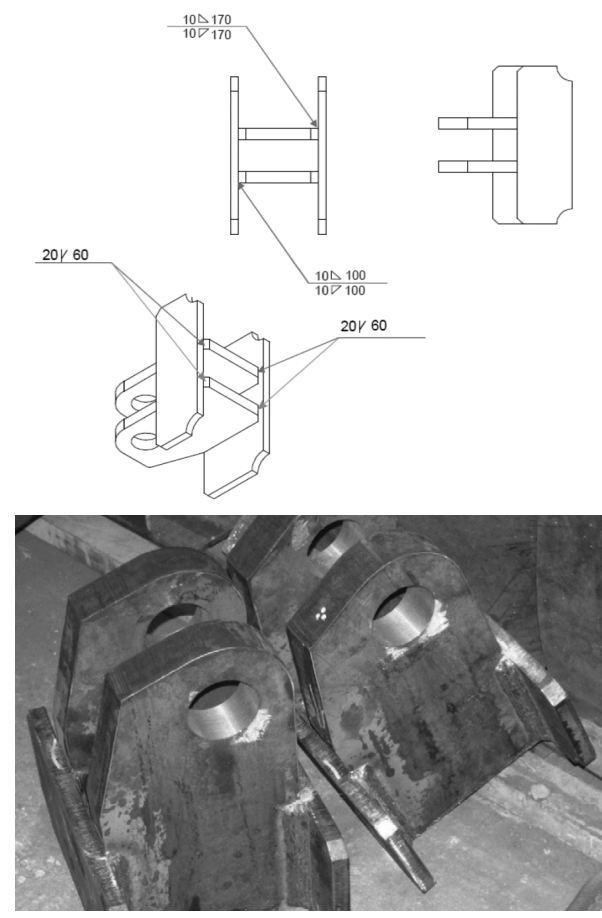

Rys. 3. Podzespół ucha cylindra

Fig. 3. A subassembly of an eye of cylinder

\section{Montaż konstrukcji}

Montaż konstrukcji osłony odbywa się etapowo z uwagi na konieczność spawania detali w odpowiedniej kolejności tak, aby możliwe było wykonanie wszystkich spoin wewnętrznych, np. przed przykryciem konstrukcji blachami poszyciowymi można było wykonać spoiny łączące tężniki (blachy główne) do blachy spodniej lub położenie spoin w miejscach trudno dostępnych.

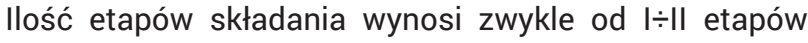
wstępnych oraz IV $\div$ VII etapów głównych w zależności od wielkości konstrukcji osłony i jej złożoności.

Etapy wstępne zwykle obejmują składanie i spawanie nakładek wzmacniajacych do tężników głównych (rys. 2), prostowanie po spawaniu oraz składanie i spawanie mniejszych podzespołów konstrukcji osłony (rys. 3), które w późniejszych etapach w całości składane są do całej konstrukcji.

\section{Obróbka wiórowa}

Po składaniu i spawaniu przedostatniego etapu i po całkowitym wystygnięciu (zwykle po 24 godz.) konstrukcje osłon rozczepia się na pojedyncze sztuki. Po rozczepieniu konstrukcja osłony poddawana jest ostatecznej obróbce wiórowej - wytaczaniu otworów głównych dla zapewnienia współosiowości (zwykle 0,1 mm) i rozstawów otworów zgodnie z dokumentacją konstrukcyjną (rys. 4).

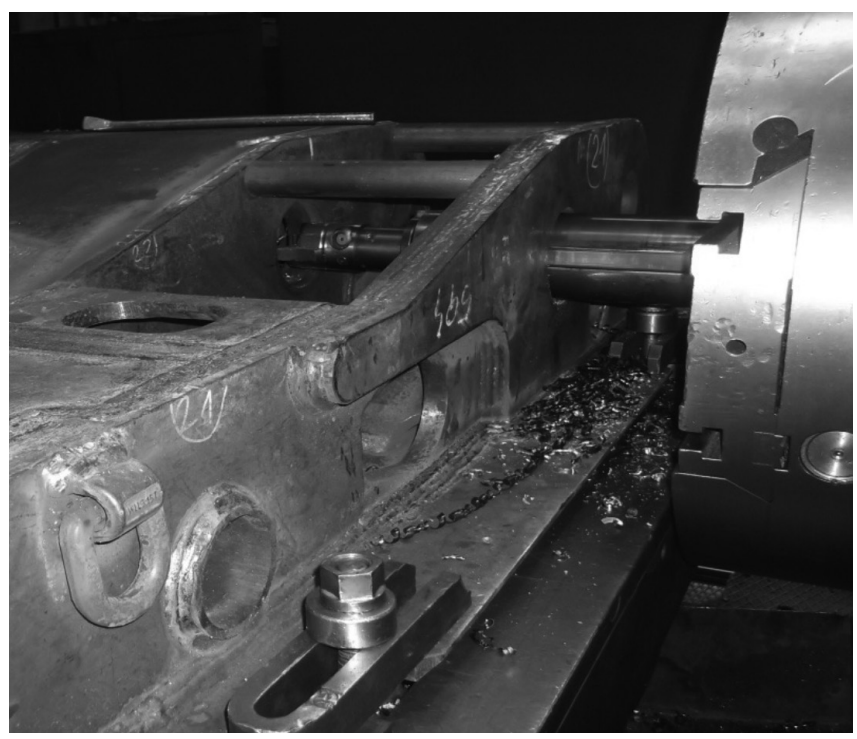

Rys. 4. Obróbka wiórowa - wytaczanie otworów głównych

Fig. 4. Machining - boring the main holes

\section{Kontrola techniczna}

\section{Kontrola wymiarowa}

Przed operacją malowania konstrukcje osłon poddawane są kontroli ostatecznej przez pracownika kontroli technicznej. Kontrola techniczna polega na sprawdzeniu poprawności wykonania konstrukcji osłony zgodnie z dokumentacją techniczną pod względem zgodności wymiarowych. Wymiary średnic i rozstawy otworów głównych oraz sprawdzanie funkcjonalności połączenia konstrukcji osłony z innymi elementami zestawu obudowy (montowalność ze stropnicą i stojakami) odbywa się przy pomocy sprawdzianów i szablonów kontrolnych. Wyniki pomiarów wpisywane są do karty pomiarowej (rys. 5) i są archiwizowane. 


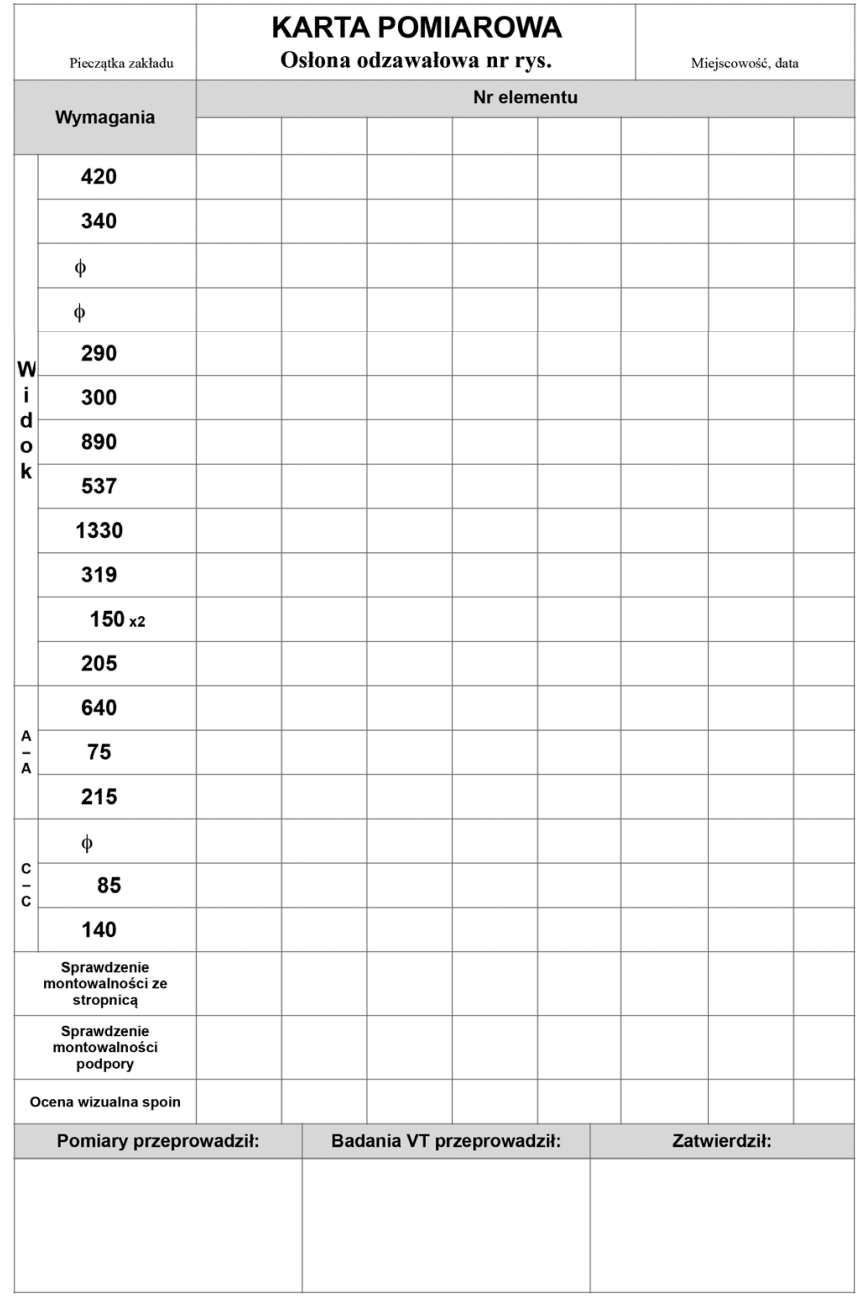

Rys. 5. Karta pomiarowa

Fig. 5. Measurement chart

\section{Kontrola złączy spawanych}

Kontrola spoin odbywa się w oparciu o kartę kontroli spoin, w której podano spoiny które muszą zostać sprawdzone zgodnie z wymaganiami PN-EN 5817 oraz rodzaj badań nieniszczących, który należy zastosować do badań.

Wszystkie spoiny bada się w $100 \%$ wizualnie (VT). Spoiny, które należy zbadać innymi metodami określa karta kontroli spoin. Zwykle spoiny pachwinowe bada się metodą magnetyczno - proszkową (MT) zaś spoiny czołowe bada się metodą ultradźwiękową (UT) (rys. 6 i 7).

Wyniki badań wpisywane są w kartę kontroli spoin i są archiwizowane.

Na rysunku 8 pokazano niezgodności - pęknięcia spoin wykryte za pomocą badania metodą magnetyczno - proszkową (MT).

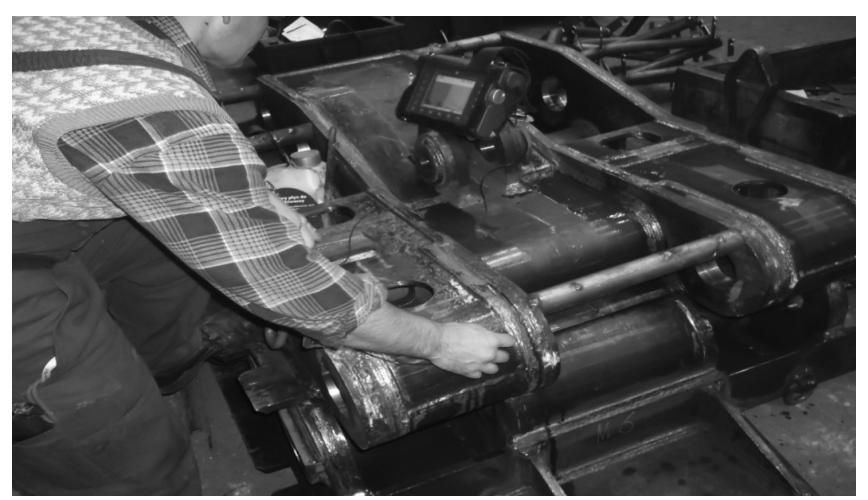

Rys. 6. Badanie nieniszczące spoin metodą (UT)

Fig. 6. Non-destructive testing of welds by (UT) method

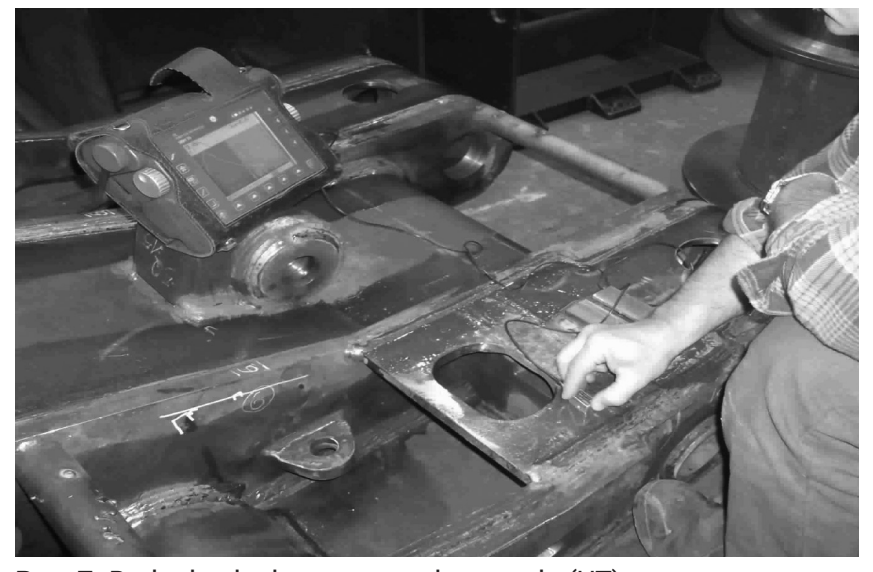

Rys. 7. Badanie nieniszczące spoin metodą (UT)

Fig. 7. Non-destructive testing of welds by (UT) method
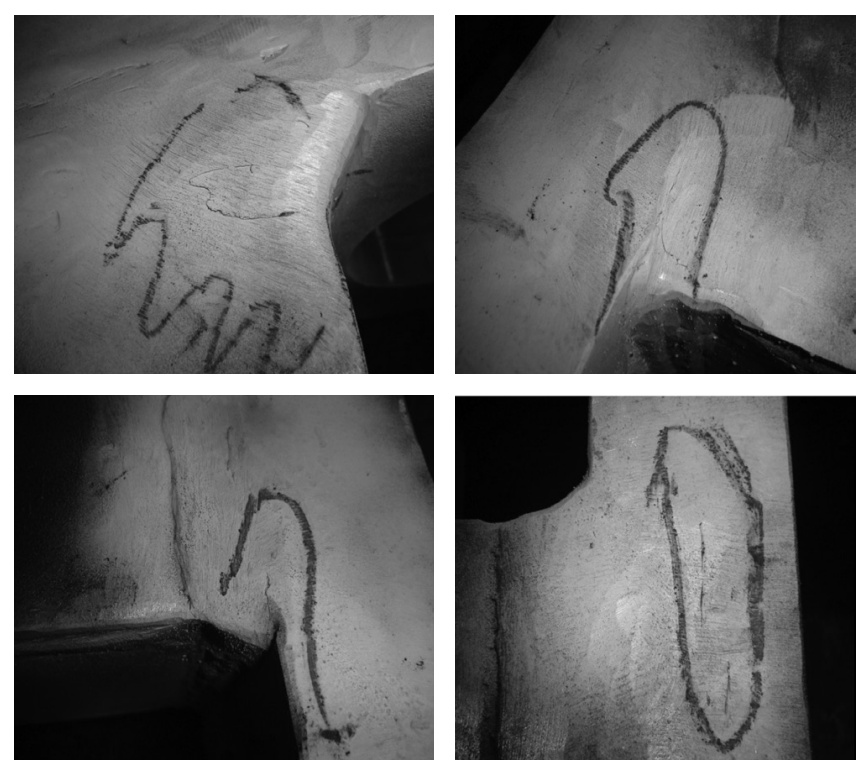

Rys. 8. Widoczne niezgodności (pęknięcia spoin) wykryte podczas badań (MT)

Fig. 8. Visible discrepancies (cracks of welds) detected during (MT) testing

\section{Proces spawania}

\section{Spawanie konstrukcji osłony}

Spawanie prowadzone jest metodą MAG (135) - spawanie elektrodą topliwą w osłonie gazów lub ich mieszanek. Spawanie poszczególnych etapów konstrukcji osłony odbywa się ściśle wg Kart Technologicznych Spawania (Planów Spawania) ogólnych i szczegółowych oraz Instrukcji Technologicznych Spawania - WPS-ów przestrzegając ściśle parametrów spawania w nich zawartych.

Źródłem prądu są półautomaty spawalnicze - spawarki inwentorowe głównie typu KEMPOWELD 5500W i FASTMIG KMS 500 firmy KEMPPI.

Materiał dodatkowy dobrano wg PN-EN 14341 - drut elektrodowy w gatunku G4Si1 (wg DIN 8559 - SG3). Jako gaz osłonowy stosowana jest mieszanka argonu i $\mathrm{CO}_{2}$. Wg PNEN ISO 14175 skład mieszanki to: 82\%Argon + 18\% CO2.

Na rysunku 9 pokazano przykładową Instrukcję Technologiczną Spawania - WPS dla złącza czołowego dla spoiny V25 i K25 z pełnym przetopem. Materiały spawane to stal niestopowa konstrukcyjna w gatunku S460, S420, S355 lub S235. W instrukcji określono min. rodzaj złącza, gatunek materiału podstawowego, metodę i pozycję spawania, parametry spawania oraz rodzaj materiałów dodatkowych - drutu elektrodowego i gazu osłonowego. 


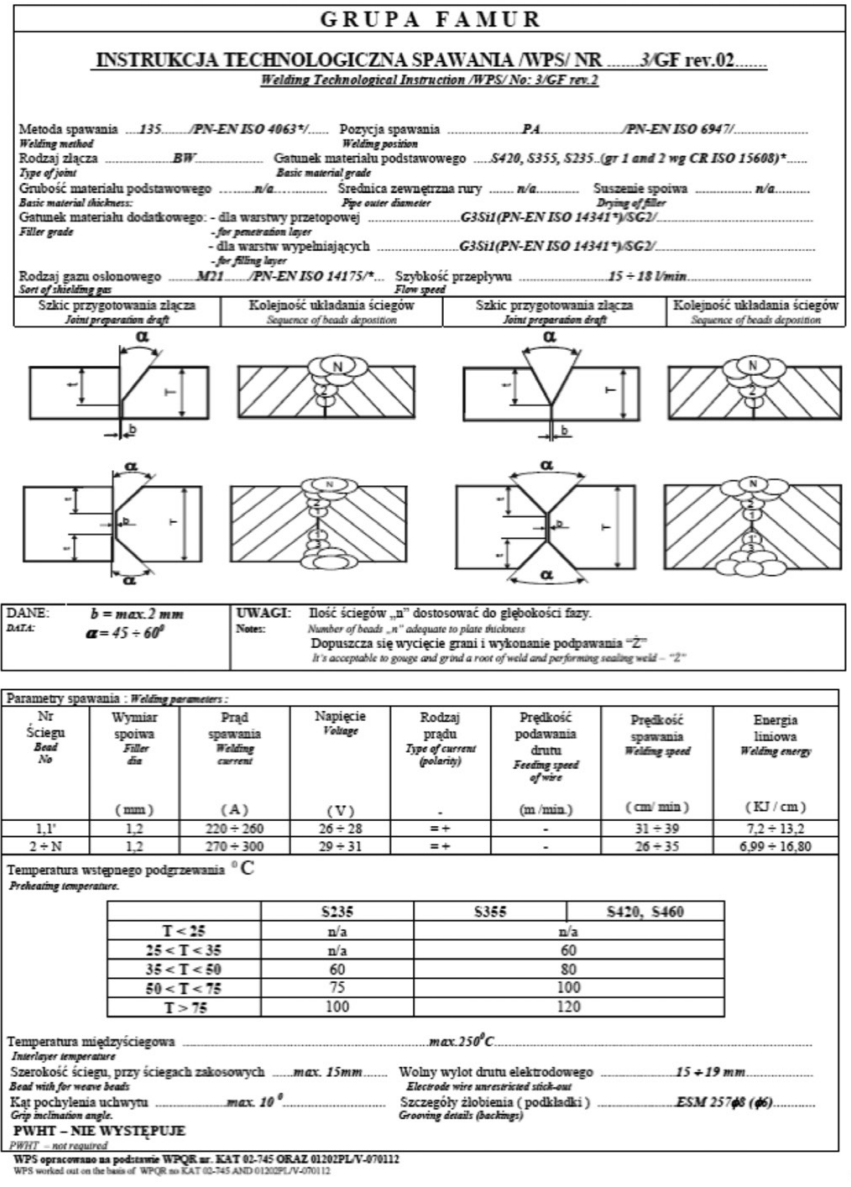

Rys. 9. Instrukcja Technologiczna Spawania - WPS

Fig. 9. Welding Technological Instruction - WPS

\section{Karty technologiczne}

Oprócz Technologicznych Planów Spawania do wykonania konstrukcji osłony stosowane są również Karty Technologiczne. Karty te tworzone są zarówno do wykonania poszczególnych detali tzw. karty detaliczne, jak również karty montażowe do wykonania składania i spawania całej konstrukcji. Karty detaliczne tworzone są dla każdego detalu osobno. W kartach technologicznych detalicznych ujęty jest proces technologiczny wykonania poszczególnego detalu od operacji cięcia termicznego (dla detali wykonanych z blach), poprzez wykonanie faz pod spoiny, szlifowanie, prostowanie, gięcie itp., aż do operacji śrutowania, która zwykle jest ostatnią operacją dla wykonania detalu przed operacją składania. W kartach technologicznych detali wymagających obróbki mechanicznej po operacji śrutowania zawarte są ponadto operacje obróbki wiórowej takie jak: wiercenie otworów, frezowanie czy toczenie.

Montażowe karty technologiczne zawierają szczegółowy opis procesu technologicznego składania i spawania wszystkich operacji:

- ślusarskich - z podaniem ilości etapów składania, numerów pozycji detali wg wykazu konstrukcyjnego i rysunku, kolejności składania detali w poszczególnych etapach, ilości detali oraz symboli przyrządów montażowych potrzebnych do danego etapu składania,

- spawalniczych - z podaniem długości spoin dla poszczególnych etapów,

- operacje obróbki mechanicznej z opisem zakresu jej wykonania,

- szlifowania wykańczającego

- śrutowania,

- malowania.

W kartach technologicznych detalicznych jak i montażowych ujęte są również zadane czasy do wykonania poszczególnych operacji. Czasy te składają się z czasu przygotowawczo - zakończeniowego (tpz.) i czasu jednostkowego (tj.).

Ponadto karty technologiczne określają stanowisko robocze dla wykonania każdej operacji oraz zawierają operacje kontroli technicznej umieszczone po każdej operacji.

Na rysunku 10 przedstawiono przykładową kartę technologiczną montażu wykonania konstrukcji osłony.

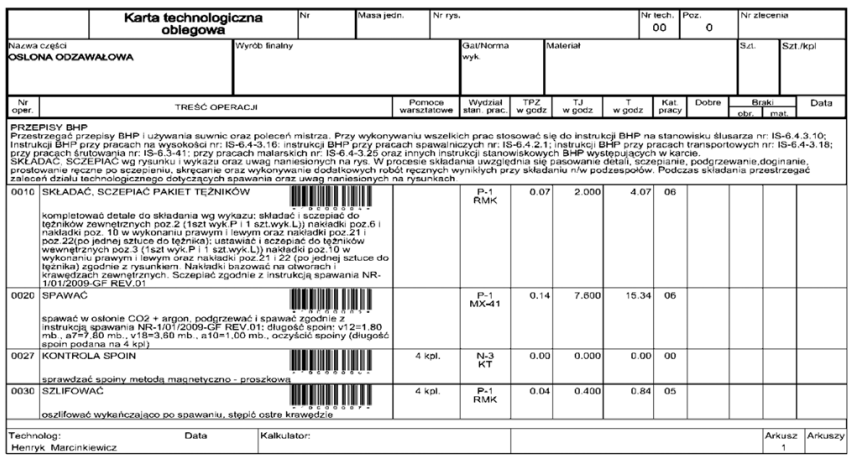

Rys. 10. Karta technologiczna montażu

Fig. 10. An assembly operation sheet

\section{Podsumowanie}

Proces wytwórczy konstrukcji spawanych prowadzony w zakładzie produkcyjnym musi przebiegać zgodnie z wytycznymi i procedurami jakościowymi wdrożonymi w zakładzie.

W zakresie spawania zakład wykonujący odpowiedzialne konstrukcje spawane musi udokumentować swoje kwalifıkacje poprzez posiadanie Certyfikatu wdrożenia PN-EN ISO 3834-2 „Wymagania jakości dotyczące spawania materiałów metalowych. Część 2: Pełne wymagania jakości", Świadectwa Kwalifikacyjnego dla I Grupy Zakładów Dużych wg PN - M69009 lub Dużego Świadectwa wg DIN 18800 cz.7, a także posiadać wdrożony System Zarządzania Jakością zgodny z wymaganiami normy PN-EN ISO 9001:2009.

Reguły wykonania, kryteria akceptacji itp. zawarte w normach i dokumentach związanych z wyrobem ułatwiają opracowanie dokumentów opisujących standardowe warunki wykonania, które powinny być zapewnione przez wytwórcę. Procesy spawania wykonywane w zakładzie ze względu na swój specjalny charakter powinny być realizowane przez kompetentny i wykwalifikowany personel spawalniczy. Zakład wykonujący procesy spawalnicze odpowiedzialnych wyrobów powinien dysponować wystarczającym i kompetentnym personelem do planowania, wykonywania i nadzorowania produkcji spawalniczej oraz powinien posiadać wykwalifikowany personel badań nieniszczących. 


\section{Literatura}

[1] Słania J., Marcinkiewicz H., Kiełbik M.: Plan spawania elementu obudowy kopalnianej - osłony odzawałowej. Przegląd Spawalnictwa 2012, nr 2, str. 6 - 16.

[2] J. Słania, P. Urbańczyk: Technologia oraz plan spawania gazoszczelnych ścian rurowych kotła pyłowego wg normy PN - EN 12952-5 . Przegląd Spawalnictwa, 2009, nr 12, st r. $19-27$.

[3] Słania J.: Technologia spawania płyty wsporczej pojazdu gąsienicowego - dobór parametrów i obliczanie kosztów spawania. Biuletyn Instytutu Spawalnictwa, 2010, nr 2, st r. 52 - 56.

[4] Słania J.: Plan technologiczny spawania płyty gąsienicowej. Przegląd Spawalnictwa, 2010, nr 3, st r. $16-25$.

[5] Słania J., Kaczor T.: Plan spawania zbiornika ciśnieniowego. Przegląd Spawalnictwa, 2010, nr 4, str. 9 - 18

[6] Słania J., Kwiecień L., Jarosiński J.: Plan spawania kotłów płomienicowo - płomieniówkowych. Przegląd Spawalnictwa, 2010, nr 6, st r. $32-40$.

[7] Słania J., Skóra J.: Plan spawania wymiennika ciepła chłodzonego powietrzem. Przegląd Spawalnictwa 2011, nr 2, st r. 16-22.

[8] Słania J.: Plan spawania carg płaszcza pieca obrotowego. Przegląd Spawalnictwa 2011, nr 2, st r. 36-41.

[9] Słania J., Wodecki D.: Plan spawania belki poprzecznej dźwigu. Przegląd Spawalnictwa 2011, nr 2, st r. 30-35.

[10] Słania J.: Istota planów spawania. Przegląd Spawalnictwa 2011, nr 2, st r. 3-9.

[11] Słania J.: Plan spawania napraw bieżących kotłów parowych, wodnych i stałych zbiorników ciśnieniowych. Przegląd Spawalnictwa 2011, nr 2, st r. 22-30.

[12] Słania J., Chomiuk S., Dadak R.: Plan spawania dla konstrukcji uzupełniającej - trawresy. Przegląd Spawalnictwa 2012, nr 2, st r. 3 - 6.
[13] Słania J., Fryc H.: Spawanie pojazdów szynowych - plany spawania. Przegląd Spawalnictwa 2012, nr 2, st r. 16 - 20.

[14] Słania J.: Plan spawania stalowej kładki dla pieszych I. Przegląd Spawalnictwa 2012, nr 2, str. 20 - 24.

[15] Słania J.: Plan spawania stalowej kładki dla pieszych II. Przegląd Spawalnictwa 2012, nr 2, str. 24 - 26.

[16] Słania J., Urbańczyk P.: Technologia wytwarzania oraz plan kontroli jakości przegrzewacza pary kotła parowego wg PN-EN 12952-5. Przegląd Spawalnictwa 2012, nr 5, st r. 29 - 41.

[17] Chromik D., Słania J.: Plan spawania ciśnieniowego zespołu rurowego. Przegląd Spawalnictwa 2012, nr 11, str. 29 - 32

[18] Balcerzak M., Słania J.: Spawanie zbiornika bezciśnieniowego do magazynowania oleju opałowego. Przegląd Spawalnictwa 2012, nr 11, str. 33 $-38$.

[19] Słania J.: Usuwanie odkształceń spawalniczych. Przegląd Spawalnictwa 2012, nr 2, str. 24 - 26

[20] Wiadomości Górnicze Numer specjalny: Obudowy zmechanizowane, Katowice 2006,

[21] PN-EN ISO 17637:2011, Badania nieniszczące złączy spawanych. Badania wizualne złączy spawanych

[22] PN-EN ISO 17638:2010, Badanie nieniszczące spoin. Badanie magnetyczno-proszkowe

[23] PN-EN 1714:2002/A2:2005, Badania nieniszczące złączy spawanych. Badanie ultradźwiękowe złączy spawanych

[24] PN-EN 12062, Badanie nieniszczące złączy spawanych. Zasady ogólne dotyczące metali. 